\title{
BIOLUMINESCENCE: TEACHING BIOCHEMISTRY BEYOND THE UNIVERSITY WALLS
}

\author{
Ana Paula Jesus de Almeida1, Marcelo Rosas Rabelo², Luzimar Gonzaga Fernandez ${ }^{3}$ \\ 1 Universidade Federal da Bahia, Biofunção (Bahia, Brasil), 2 Universidade Federal Bahia, Bioquímica Metabólica \\ para Farmácia (Bahia, Brasil), 3 Universidade Federal Bahia, 3Laboratório de Bioquímica, Biotecnologia, \\ BioprodutosLBBB/ICS/UFBA, Departamen (Bahia, Brasil)
}

INTRODUCTION: The use of video in teaching and learning processes provides a challenging environment, able to stimulate the intellect and facilitate understanding in life science studies. Videos can be of extraordinary importance in education and dissemination of knowledge, contributing to greater learning, but is rarely used and exploited properly, especially for teaching biochemistry. Biochemistry is considered complex because it involves many molecular structures and processes, especially considering the number of events and molecules involved in the metabolism. OBJECTIVES: This study aimed to introduce biochemistry for the students of basic education using the theme "Light, Science and Life" in a playful and fun way. MATERIALS AND METHODS: A video about bioluminescence was designed and prepared aiming to use it as a support for learning biochemistry by students of basic education of public schools located in Salvador, Bahia. In order to prepare the video, undergraduate students initially revised the literature in order to acquire proper knowledge, and along with their teacher advisor worked the elaboration of texts, textbook and questionnaire and applied at school. DISCUSSION AND RESULTS: Analysis the qualitative results of the experiment on the preparation and use of the video about "Bioluminescence" focused mainly on the content of biochemistry linked to theme Light, Science and Life, and demonstrated the importance of such work in the teaching-learning process. The dynamics used allowed greater interaction between students and teacher, and the teaching of biochemistry in a fun way beyond the university walls. CONCLUSION: The teaching through recreational resources, e.g. videos and other educational strategies that foster learning should be encouraged from basic education, always bearing in order to transmit through these teaching methods the main concepts covered in biochemistry.

Keywords: luciferase; teaching and learning; basic education 